\title{
Feasibility and Effect of Adding a Concurrent Parental Component to a School-Base Wellness Program Using Two Modes of Mobile-Based Technology - Mixed Methods Evaluation of RCT
}

Moria Golan ( $\nabla$ moria.golan@mail.huji.ac.il )

Tel Hai Academic College

Shakked Benifla

Tel Hai Academic College

Aviv Samo

Tel Hai Academic College

Noa Alon

Tel Hai Academic College

Maya Mozeikov

Tel Hai Academic College

\section{Research Article}

Keywords: School-based, Prevention, Self-esteem, Body esteem, Mobile application

Posted Date: September 17th, 2021

DOl: https://doi.org/10.21203/rs.3.rs-618752/v1

License: (c) (1) This work is licensed under a Creative Commons Attribution 4.0 International License.

Read Full License

Version of Record: A version of this preprint was published at BMC Public Health on February 14th, 2022. See the published version at https://doi.org/10.1186/s12889-022-12581-7. 
2 Feasibility and Effect of Adding a Concurrent Parental Component to a School-

\title{
Base Wellness Program Using Two Modes of Mobile-Based Technology - Mixed Methods Evaluation of RCT
}

\author{
Moria Golan $^{1,2}$, Shakked Benifla ${ }^{1}$, Aviv Samoํ, Noa Alon ${ }^{1}$, Maya Mozeikov ${ }^{1}$ \\ ${ }^{1}$ Department of Nutritional Sciences, Tel Hai Academic College, Kiryat Shmona, Israel \\ ${ }^{2}$ Shahaf, Community-based body image and eating disorders facility, Israel
}

\section{Corresponding author:}

Prof. Moria Golan, moria.golan@mail.huji.ac.il

\section{Abstract}

Background: This study assessed the feasibility and effect of two mobile modes (WhatsApp vs. a specially designed app) in their delivery of updates and assignments to parents.

Methods: Two three-armed, randomized, controlled feasibility studies were conducted. Participants were randomly allocated to the control arm, youth-only arm, or youth \& parental component arm. In the parental component, parents received updates and were requested to complete shared assignments with their children. In the first year, the assignments were sent through WhatsApp and in the following year via the specially designed smartphone application. Students and parents filled out questionnaires at three measure points: pre and post intervention and at three months follow-up. Mixed-methods assessments were performed using semi-structured interviews with parents and school staff members, as well as a computerized self-report questionnaire.

Results: The addition of the concurrent parental component via WhatsApp was associated with superior improvement in self-esteem and identification of advertisement strategies, compared with 
the youth-only program. However, adolescents in the youth-only program delivered via the specially designed application demonstrated superior improvement compared to those in the youth and parental component arm.

Conclusions: Although the addition of the concurrent parenting component was praised by the actively participating parents, overall, this intervention was not statistically superior to the youthonly arm. Only a few variables demonstrated statistically significant improvement, usually with a small effect size. The use of WhatsApp had higher feasibility and uptake than the use of the specially designed application.

Under the chosen structure and population, it seems that the program did not have the intended impact. Parents who expressed specific resistance may have negatively affected their children, causing them to be less engaged. A cost-benefit analysis of programs with parental components as well as the development of strategies to enhance parent-school partnership are warranted.

Trial registrations: NCT04129892 (1.11.2017) and NCT03540277 (26.4.2018)

Keywords: School-based, Prevention, Self-esteem, Body esteem, Mobile application

\section{Background}

Prior research demonstrates the positive impact of parental involvement on children who participated in various school-based prevention programs [1-3]. Findings from previous studies suggest a relationship between parental involvement in youth programs and improved parent/child communication, bonding, and perceptions of one another. In addition, having common ground experience prolonged the positive post-participation effects of the experience [4].

Although parents acknowledge the importance of children's physical and mental health as well as changing attitudes toward increased parent-school collaboration, few parental component implementation studies on prevention programs in general and positive body and self-esteem prevention programs among adolescents in particular have been conducted. A systemic review of the parental component in prevention programs reported that most programs included a minimal or 
unassessed parental component. However, many of those that provided a more substantive intervention component for parents failed to recruit or retain sample sizes sufficient to allow statistical significance testing [5].

While involving parents appears productive in theory, it is quite different in practice. Parents' own negative school experiences are likely to cause an undesirable impact, thus inducing an adverse avoidance reaction to nonmandatory assignments among their children. Further, uptake, engagement, and the retention of parents in prevention programs are ongoing challenges. Parental attendance rates in family-based programs typically range from 35-50\%, and up to one-third of those who enroll do not attend any of the sessions [6]. Family characteristics and competing responsibilities among dual-earner households and parents with more than two children were associated with lower program enrolment. To address the notable disparities in access to evidence-based, cost-effective parenting interventions [7], and to overcome parental engagement barriers as well as enhance prevention program effectiveness, technology-based methods are employed in parenting programs [8]. The prominent use of smartphones among adolescents and their parents has led to an increase in healthrelated apps [9]. Moreover, digital interventions may also enable researchers to access geographically distant and busy parents [10], while addressing participants' anonymity concerns. Although the efficacy of smartphone-delivered interventions is emerging, high rates of attrition and low adherence were reported, both of which threaten the validity of randomized controlled trial findings [11].

In school-based programs, the headteacher and senior management team encourage parental involvement to improve parental uptake. Moreover, parenting involvement is successful when it is part of the school's ethos and is developed and delivered as "a whole school approach" [12]. Proactive relationship building with parents via telephone, or in-person pre-program contact was recommended to increase parental engagement. Further, providing update letters with shared assignments and adjunct support were some of the multi-component approaches suggested (e.g., information sheet, short video) [13, 14]. 
As there is a lack of research on the best practices for parental engagement in shared assignments with their early-adolescents, the current feasibility studies assessed the effectiveness of implementing an evidence-based, school-based wellness program, with and without parental collaboration, through updates and shared tasks on adolescents' self-esteem and body esteem. The studies primarily aimed to assess the feasibility and acceptability of two mobile modes in terms of delivering updates and assignments to parents: WhatsApp vs. "Young in favor of myself," a specially designed application. We hypothesized that using the program's specially designed application to contact parents and deliver the shared assignments would produce better uptake and parental engagement than when delivered via WhatsApp. The second aim was to assess the impact of the additional parental component on adolescents' perceptions and behaviors. The main hypothesis was that adding a parental element to extend adolescents' exposure and engagement to the prevention program's topics would result in superior self-esteem and body esteem, self-care, and media literacy.

\section{Methods}

\section{Design and sample recruitment}

The two-year randomized clinical trial tested the feasibility, acceptability, and impact of "Young in favor of myself," a manualized universal, interactive intervention program for young adolescents (5th graders) and their parents. Principals and school counselors of all elementary schools in northern Israel were contacted.

The eligibility criteria for schools included: a) having at least two 5th grade classes; b) agreement to schedule the program lessons on Mondays and Thursdays, due to the availability of the students facilitating the research; c) commitment to provide an appropriate room for each of the groups; and d) commitment to the presence of a class teacher or school counselor during the sessions to ensure appropriate behavior. Four schools were eligible to participate in each of the two-year trials.

\section{Randomization and blinding}



research assistant blinded to their characteristics. Using the randomization function in Microsoft Excel, each year, schools were randomly assigned to one of the three study conditions: a) control condition, b) youth-only intervention, and c) youth with concurrent parental component condition.

Schools were used as selection units to avoid contamination bias due to communication about the intervention between participants and controls within each school. Schools were blinded to condition allocation. Differences in the baseline sample size in each arm were due to varying class sizes in each school.

\section{Study population} (No 12/2017/-1 and 08/2018-4). The trial methods and analysis strategy were pre-registered. The universal trial registration numbers are NCT04129892 (1.11.2017) and NCT03540277 (26.4.2018). 
study and provided informed consent. All methods were performed in accordance with the Declaration of Helsinki and Consort 2010 guidelines and regulations.

\section{Interventions}

\section{Youth control arm}

The control groups in both studies received three health- and nutrition-related sessions conducted by graduate students of Nutritional Sciences.

\section{Youth intervention arms}

"Young in favor of myself" is an interactive program comprising 10 weekly, 90-min sessions on self-care behaviors, media literacy, self-esteem, and positive body image. It is an evidence-based intervention that was empirically supported and substantiated with research findings that demonstrate beneficial and predictable outcomes [15] (Table 1).

The program included a kit with background material, a detailed guide for facilitators with structured session plans, a framework for each topic, and interactive activities to engage participants verbally and non-verbally. To trigger situational interest, we used hands-on activities, novelty, surprise, and group work. Age-tailored games were often incorporated into the sessions. The program was semi-structured, with flexibility that enabled facilitators to be creative while addressing their groups' specific needs, as was suggested by Slaten and Elison's [16]. Group facilitators were undergraduate students of Nutritional Sciences and Education, who received intensive training and supervision by the program's founder and an expert social worker throughout the intervention.

\section{Youth intervention with parental component}

The parental component included weekly updates for parents about the current topic of discussion in the class. Moreover, one or two of the suggested shared assignments for parents and children were delivered concurrently with the "Young in favor of myself" class-based sessions. For instance, parents and children were required to describe two rights and two responsibilities the child gained in the last two years for the session on "growing up." 
motivate parents to engage and complete tasks, families received one "star" for each submitted assignment. Families who completed all tasks received a voucher for a family bowling game, to further encourage program adherence.

In the first year, the parental component was delivered via the WhatsApp application, while in the second year, it was delivered via the "Young in favor of myself" smartphone application, specially designed and programmed for this purpose (Figure 1).

\section{Study questionnaire and data collection procedures}

The computerized study questionnaire was completed online by participating students and parents via the Qualtrics XM Platform $\odot, ~ 2019$, under the supervision of program facilitators and a research student. Self-report questionnaires were preferred for participant confidentiality. Adolescents and parents completed the same questionnaire at three measure points - at baseline, program conclusion (two months later), and follow-up (three months after program conclusion). Qualitative research aimed to better understand participants' motives, incentives, and ideas about improving the program content, activities, or dissemination [17]. Personal and group semistructured interviews were conducted with selected schoolteachers and parents at program cessation to gain insights into program content, acceptability, satisfaction, and implementation.

\section{Outcome measures and variables}

Standardized instruments were used to measure program efficacy (Table 2). The preintervention questionnaire included demographic items on gender, age, familial status, and sociodemographic status. The post-intervention questionnaire consisted of a satisfaction assessment and an attendance report. All scales included in the study questionnaire were previously validated, Hebrew-translated versions.

\section{Outcome measures}


The Rosenberg Self Esteem Scale [18]. The scale consists of 10 items rated on a four-

point Likert scale. Items 1, 3, 4, 7, and 10 are scored from strongly agree (3) to strongly disagree (0), while items $2,5,6,8$, and 9 are reverse scored. The total scores range from $0-30$. Scores from 1-25 indicate a normal range; scores below 15 suggest low self-esteem, while scores above 25 indicate high self-esteem. Cronbach's alphas in these studies were $0.79,0.74$, and 0.814 for the control, youth-only, and parental component groups, respectively.

Self-Caring Questionnaire. Developed by Prof. Moria Golan, this questionnaire includes 20 items on personal and sleep hygiene, mealtime behaviors, and personal space. Items are rated on a five-point scale from never (1) to always (5) and higher scores indicate higher self-care behaviors [19]. The questionnaire was adapted for the parental version to include 20 additional items in which the parents responded according to their children's as well as their own behaviors. Psychometric qualities assessed in a small pilot study $(\mathrm{N}=10)$ revealed a Pearson Correlation Coefficient of 0.69 for reliability and Cronbach's alpha of 0.85 for internal validity. However, in the current studies Cronbach's alpha was only 0.66.

The Body Esteem Scale was used to assess body perceptions. The scale consists of 23 items divided into three subscales: appearance, weight, and attribution. The mean total and subscale scores are rated on a five-point Likert scale from never (1) to always (5). Higher scores represent higher body esteem [20]. Cronbach's alphas in these studies were $0.79,0.89$, and 0.85 for the control, youth-only, and parental component groups, respectively.

The Eating Disorders Examination Questionnaire-8 adapted for children (ChEDE-Q-8) was used to assess eating disorder symptoms. The eight-item version of the original 28 -item EDEQ has excellent item characterization with high reliability. A strong correlation was found between the eight-item version and the original EDE-Q $(r=0.97, P<0.001)$. For each statement, participants are asked to mark the frequency of occurrence in the past 28 days, and higher scores indicate a higher risk for eating disorders [21].

The advertising scale contains one item to measure participants' identification of media strategies - a known protective factor. It includes eight different strategies, from which participants 
are required to choose; identifying a higher number of strategies indicates better media literacy [22].

The 'Pressures by Media' subscale of the Sociocultural Attitudes Towards Appearance Questionnaire-4 (SATAQ-4) was used to assess participants' responses to media. Participants were instructed to rate their agreement with each item using a five-point Likert-type scale from definitely disagree (1) to definitely agree (5). A higher average score indicates higher pressures by the media to change one's appearance [23].

\section{Sample size and data analysis}

The sample size was calculated for a moderate expected effect $(f=0.25), 80 \%$ statistical power, and an $\alpha$ level of 0.05 , which was relative to the improvement in the Rosenberg Self Esteem Scale [24] and based on our previous data [19]. Calculation using G* Power software version 3.1.9.4 yielded a sample size requirement of 108 participants in all groups (parental component arm, youth-only intervention, control). Accounting for a 20\% dropout rate, the total required sample was 120 participants in the three groups for each study. All analyses were conducted using IBM SPSS Statistics for Windows version 24, IBM Corp., Armonk, NY, 2017.

In the first study (WhatsApp), only those who completed the research questionnaire at two assessment times were included in the analysis. In the second trial (specially designed application), only those who completed the questionnaire at all three assessment times were included in the analysis, to prevent imputation bias. When data in this trial were analyzed with all participants who completed only two assessments, similar results were reached. The demographic variables between those who completed three questionnaires and those who completed less than three questionnaires were not statistically significant.

Data were checked for normality using histograms, scenes, and the Kolmogorov-Smirnov test through the Box test and Levene test. Sphericity was assessed through the Mauchly test and the assumption of the equality of variance-covariance matrices. The outcome data for the first study (WhatsApp) were analyzed using multivariate analysis of variance models by calculating the deltas 
between measure points (T2-T1, T3-T1) and using Bonferroni post hoc analyses between study groups.

In the specially designed application (second study), categorical demographic characteristics were presented as frequencies and percentages, and the association with study groups was tested using chi-square tests. Continuous demographic characteristics were presented as mean and standard deviation, and the differences between study groups were tested using the Kruskal-Wallis Test.

Most of the measures in this study (specially designed application) were not normally distributed and were therefore analyzed using non-parametric tests. Friedman tests were used to examine the differences between study times within each group, and Kruskal-Wallis tests were used to examine differences between the three study groups at each time point. Personal self-care hygiene and SATAQ-4 were tested using mixed model analysis. The effect size was marginal $\mathrm{R}^{2}$ for the mixed models, eta-squared for the Kruskal-Wallis Test, and Kendall's W for the Friedman test.

For the qualitative analysis, all semi-structured interviews were audio-recorded and transcribed. The interview included questions on participants' understanding of the program aims, barriers and facilitators to engagement, satisfaction from the topics and activities, and acknowledgments of change among their children.

The data were analyzed by identifying recurring key themes, which represented ways of understanding the combined meanings within the texts [25]. We chose a meta-ethnography analysis, widely used to qualitatively synthesize data in health and social care research [26].

Following the thematic analysis, we attempted to build a general interpretation based on the data [25]. This interpretive layer enabled deeper insights into the barriers faced in disseminating and implementing parental components in school-based prevention programs.

\section{RESULTS}

\section{Responsiveness of adolescents and parents}


2633 and Figure 2). The concurrent parental arm demonstrated higher resistance to participate in the study, with the lowest percentage of consenting parents and the lowest rate of adolescents who completed the questionnaire at all assessment times, found in both digital modes.

The WhatsApp mode of delivery was associated with $12 \%$ of allocated participants declining to provide consent for their children to participate in the accompanying research. In comparison, $38 \%$ declined to consent when the specially designed application was employed.

Over time, the decrease in adolescent engagement was the lowest in the youth-only arm compared with the control group. A greater reduction in session attendance was found among adolescents in the parental component arm. Overall, the study groups and research stages show a significant superiority in participant responsiveness to WhatsApp as compared to the specially designed application (Table 3 and Figure 2). No significant differences were found in baseline demographics and outcome characteristics between participants that completed the three research questionnaires and those that did not.

\section{Qualitative interviews}

Conducted after program termination, these interviews shed light on parental and school team perceptions regarding addition of the parental component to the school-based wellness program. Five major themes emerged in the qualitative component of this study:

1. Most parents perceived school activity as a burden. "...leave us in harmony with our children, don't interfere with the house schedule and type of conversation. I know you have good intentions, but I prefer if the schoolworks within its territory and does not enroll me for shared tasks" (H.I.). "It is so hard to manage with four kids... the competing demands are my priority and not the suggested shared tasks...Moreover, my child is healthy; we don't need it. Deliver it to parents with problematic children" (R.B.).

2. Rule enforcement. School teachers perceived the engagement of parents as necessary but preferred not to confront parents who expressed silent resistance. "The contents and the activities 
are great and age appropriate. However, most parents choose not to cooperate, and I prefer to choose my battles. If a parent chose not to cooperate, I will not penetrate his territory. I have to respect his avoidance. Personally, I admit, I am not particularly eager to cooperate when my child's school enrolls me in activities" (M.C.). "I did not choose this program, and it does not address my priorities in being involved in the schools' activities." (B.R.)

3. Parental resistance to consent to participate in the research. Parents explained their resistance to participate due to privacy threat, fear of exposure, and law literacy regarding their and their children's benefit from the research process. "Why should my child and I be like an experimental

4. Preference of WhatsApp usage over unique applications due to technological barriers and privacy

\section{Baseline descriptive characteristics of participants}


In both studies, the mean age of all youth participants, both male and female, was 10.1 years

$(\mathrm{SD}=0.3)$. Groups appeared to be well balanced on baseline demographic characteristics (Table 4) as well as baseline outcomes values (Table 5). This was observed when data analyses were applied on the sample that included participants who completed at least two questionnaires as well as when only those who completed all three assessment questionnaires were included.

\section{Intervention efficacy}

$$
\text { Self-care (Table 6) }
$$

Personal self-care hygiene was not affected by the trial condition in either digital mode. A statistically significant interaction of group $\mathrm{X}$ time was found $\left(p<0.001 ; \mathrm{R}^{2}=0.03\right)$ with a small effect size with superiority in the control group.

Self-territory care was not affected by group or by times in either study. Nevertheless, in the specially designed application (second study), there was a statistically significant group X time effect with superiority (small effect size) in the concurrent parental component arm, along with all assessment times compared with the other two groups.

\section{Self-esteem}

In the WhatsApp mode (first trial), there was a statistically significant group effect with a small effect size $\left(p<0.005 ; \eta^{2}=0.04\right)$ on youths' self-esteem in the parental component arm at post-intervention. This improvement diminished at the three-month follow-up (Figure 3).

In the second trial (specially designed application), a statistically significant change in youths' self-esteem was also found at the follow-up assessment. The improvement was larger in the control (moderate effect size) and youth-only arms (small effect size), with no statistically significant change in the parental component arm (Table 7).

\section{Body esteem}

In the WhatsApp mode (first trial), there was no effect of trial conditions on either of the body-esteem subscales. In the specially designed application mode (second trial), there was a statistically significant effect of group on the body-esteem-appearance subscale, at program termination, with statistically significant superiority in the youth-only arm at post-intervention as 
well as at the follow-up assessment (small effect sizes). In the weight subscale, there was no group or time effect. However, there was a statistically significant interaction of group $\mathrm{X}$ time with superiority in the control group at the follow-up assessment, with moderate effect size. (Table 8).

\section{Media literacy}

Media literacy was assessed using the number of advertisement strategies identified and the perception of being influenced by media pressures to change one's appearance.

In the WhatsApp mode (first trial), the youth-only arm and the concurrent parental component arm demonstrated a statistically significant superiority and increase in identifying advertisement strategies over time compared with the control arm (Figure 4) with a large effect size $(\eta 2=0.264)$. No effect of trial conditions was found on the perceived pressure experienced by the media to change appearance (SATAQ-4).

In the specially designed application mode (second trial), there was no effect of trial conditions on the number of advertisement tactics identified by youth and on perceived pressure imposed by the media to change appearance (SATAQ-4). Nevertheless, when youth responses were divided into those under 1 (not affected by media) and above 1 (affected to a large extent), the analysis revealed a decrease of $29 \%$ in the control group among youth being affected (from $73.7 \%$ at baseline to 44.7 at follow-up). Moreover, a $31 \%$ reduction (from $64 \%$ to $33 \%$ ) in the youth-only arm and a $14 \%$ reduction in the parental component arm (from 68\% at baseline to $54 \%$ at followup) were found. Mixed model analysis revealed a statistically significant effect of group $\left(\chi^{2}=6.44\right.$; $p<0.05)$, time $\left(\chi^{2}=20.96 ; p<0.001\right)$, and time $\mathrm{X}$ group $\left(\chi^{2}=13.27 ; p<0.01\right)$.

\section{Eating disorders behaviors}

There was no effect of trial conditions or study arms on the eating disorders' behavior scores. At all assessment points, the scores were far below the cut-off for identifying pathology in this age group.

\section{Discussion}

There is robust evidence of the associated positive outcomes of parental engagement in school-based prevention programs [27-29]. This evidence is consistent with Bronfenbrenner's ecological systems theory $[30,31]$, which proposes that interactions with parents around learned 
topics at school might help address internalizing concerns [4, 32]. Digital-based prevention programs were suggested for this purpose [33-35].

The current study examined the feasibility and impact of concurrent parental components (parents receive updates and shared assignments with adolescents) integrated into "Young in favor of myself," a school-based interactive wellness program for 5th grade primary school students. The parental component includes weekly topic update letters to parents, with suggestions for dyadshared assignments. A prior study has suggested this strategy to avoid parents from falling into the role of disciplinarians [4].

The current study revealed that parents' engagement in the shared assignments was shortterm only and deteriorated during trial times. Participants' attrition presents a significant problem for even the most well-planned and well-executed intervention projects with internal and external validity and facilitator motivation. For instance, Amaral et al. reported that 50\% of intervention participants attended all four prevention program sessions and completed the posttest assessment [34]. Morgan et al reported that only $38 \%$ of the parents that participated in mental health first aid training completed the 3-yrs follow-up assessment [35]

However, the retention rate was higher when the concurrent parental component was delivered by WhatsApp than by a specially designed application. The application was designed to create an intimate environment where parents could consult the specialist who developed the shared assignments, and ask personal questions related to the discussed topics, anonymously or openly. Moreover, this platform was intended to serve facilitators by sending memos and funny responses to generate continuity and engagement with the program topics. In contrast to our hypothesis and expectations, parents expressed resistance to downloading the specially designed application. Although parents believed in the program's importance and shared the school's interest in preventing risk behaviors, they did not perceive the program as being their choice or as reflecting their needs and interests. Although most parents (not all) provided consent, they easily withdrew their consent when it came to implementation. From the perspective of an external supplier, the 
partnership between parents and schools felt weak, and contributed to the barriers in implementation and adoption of prevention programs.

Barriers, such as technical difficulties, fear of exposure, concerns about privacy, and lower motivation to collaborate on shared assignments were explored retrospectively through qualitative interviews. Similar barriers were reported in studies that implemented parental components in school-based prevention programs [36]. These barriers may be attributed to the rapid proliferation of social networking that has transformed the way people socialize and communicate [37]. Parents, like other human beings, are more concerned with their freedom and privacy owing to the developed vigilance toward technology and media penetrations. As was shared in the personal interviews, parents tend to develop negative attitudes to experimental research and prevention programs that were not personally chosen by them, sometimes unconsciously. The shift from worshiping the collective and the community to individuality in western societies [38] is also expressed in the imbalanced parent-school partnership. It seems, as years go by, the relationship between parents and the education system shapes the feasibility and effectiveness of school-based prevention programs. Often, shared parent-child school-based assignments tend to trigger responses to the intervention itself, thus failing to address the program objectives [39].

In contrast to the current study hypotheses and others' findings, our statistical comparisons revealed that the addition of the parental component was not statistically superior to the youth-only arm. Thus, under the chosen structure and population, the program did not have the intended impact. Moreover, parents' resistance to the parental component may have induced negative attitudes among their children, thus diminishing their ability to be positively influenced by the program content, as seen in the described trials' effects.

Further, it seems that WhatsApp was preferred by adults over the specially designed application. This may be attributed to the perceptions that WhatsApp is more intimate [40]. Moreover, the specially designed application provoked resistance due to the need to download "one more temporarily used item to the mobile phone" as was suggested in the qualitative interviews. 
Overall, the study groups and the research stages showed a significant superiority in

participant responsiveness to WhatsApp over the specially designed application. The concurrent parental component via WhatsApp was associated with statistically significant improvements in only two measures out of the seven outcome variables and only one statistically significant improvement in the youth-only arm. The concurrent parental component delivered via the specially designed application mode showed a statistically significant improvement in only one out of the seven measures. The youth-only arm showed statistically significant improvements in three out of the seven outcome measures. However, the small effect size of most changes may suggest that a larger sample size and more intensive exposure are needed for future assessments. Four statistically significant improvements were found in the control group, which received a shorter intervention. Due to higher attrition in this group (control arm of the second trial), the outcomes may be attrition biased. Morgan et al [35] who studied the long-term effect of prevention program reported that between baseline and 3-year follow-up, there was a non-significant reduction in adolescent cases of mental health problems relative to the control group (odds ratios (OR) 0.16-0.17), a non-significant improvement in parental support reported by adolescents with a mental health problem (OR 2.804.31), and a non-significant improvement in the quality of support that parents reported providing to their adolescents with a mental health problem $(d=0.38)$. The only maintained achievements parents' improved knowledge about mental health problems. Both Morgan's et al. and our results question the contribution of parental component in school-based programs.

\section{Strengths and limitations}

This study has several strengths. First, two active control groups were used; one youth-only group, without the parental component, and another with a shorter intervention to control expectancy effects. Second, the combination of quantitative and qualitative research methods deepens the understanding of the implementation of the parental component arm.

The current study has a few limitations. First, as mentioned before, attrition bias may contribute to the study outcome. Despite this, no effects on outcomes were found in comparing the analyses between participants who submitted the shared assignments and those who did not, as well 
471 SATAQ-4

$472 \quad$ OR

$473 d$

\section{Conclusions}

as in the analyses between those who completed two vs. three questionnaires. Second, the findings of this study are based on self-reports, which could be subject to social desirability bias.

Additionally, our results may not be representative of the preadolescent population as this study was performed with a selective population in a small country. Thus, conclusions should be interpreted with caution. Nevertheless, the consistent non-significant effect of the experimental parental component on most measures supports the robustness of the findings, despite the limitations and the fact that the study findings contrasted with the research hypothesis.

The use of the WhatsApp application had higher feasibility and uptake than the use of the specially designed application. Although parents and school team members expressed a positive stance toward shared assignments, poor uptake, dropout, and noncompliance may hinder the validity of our findings. Moreover, the relatively low rate of parental cooperation and the small effect sizes raise questions regarding the cost-effectiveness of adding a parental component to universal school-based prevention programs. Future studies should strive to overcome parental resistance as well as improve parent-school collaboration. Moreover, a cost-benefit analysis of parenting programs is critical for scaling up prevention programs.

\section{List of abbreviations}

RCT randomized clinical trial

app application

\section{ChEDE-Q-8 The Eating Disorders Examination Questionnaire-8 adapted for children} Sociocultural Attitudes Towards Appearance Questionnaire-4 odds ratios

d cohen effect size 


\section{Declarations}

\section{Ethics approval and consent to participation}

The Tel Hai Academic College Institutional Review Board approved the research protocol (No 12/2017/-1 and 08/2018-4). The trial methods and analysis strategy were pre-registered. The universal trial registration numbers are NCT04129892 (1.11.2017) and NCT03540277 (26.4.2018). Parents of students at all eligible schools received information about the program and the research study and provided informed consent. All methods were performed in accordance with the Declaration of Helsinki regulations and Consort 2010 guidelines.

\section{Consent for publication}

Not applicable

\section{Availability of data and materials}

The data that support the findings of this study are available from the first author upon reasonable request and with permission of The College IRB. Restrictions apply to the availability of these data by the ministry of education, and so are not publicly available.

\section{Competing interests}

The authors declare that they have no competing interests.

\section{Funding}

Tel Hai Academic College research authority funded both studies. They had no role in the design, collection, analysis, and interpretation of data and in writing the manuscript.

\section{Authors' contributions}

All authors contributed substantially to this paper. MG contributed the first draft. SB, AS and NA provided the qualitative and quantitative information. MM produced the figures and tables and reviewed the paper. All authors have read and approved the manuscript.

\section{Acknowledgement}

We would like to thank Editage (www.editage.com) for English language editing. 


\section{References}

503

504

505

506

507

508

509

510

511

512

513

514

515

516

517

518

519

520

521

522

523

524

525

526

527

1. Alfredsson EK, Thorvaldsson V, Axberg U, Broberg AG. Parenting programs during adolescence: Outcomes from universal and targeted interventions offered in real-world settings. Scand J Psychol. 2018;59:378-91. doi:10.1111/sjop.12446.

2. Barlow J, Coren E. The effectiveness of parenting programs: A review of Campbell Reviews. Res Soc Work Pract. 2018;28:99-102. doi:10.1177/1049731517725184.

3. Hill KE, Hart LM, Paxton SJ. Confident body, confident child: outcomes for children of parents receiving a universal parenting program to promote healthful eating patterns and positive body image in their pre-schoolers. An exploratory RCT extension. Int J Environ Res Public Health. 2020;17(3):891. doi:10.3390/ijerph17030891

4. Duerden MD, Witt PA, Harrist CJ. The impact of parental involvement on a structured youth program experience: A qualitative inquiry. J Youth Dev. 2013;8:106-23. doi:10.5195/jyd.2013.88.

5. Hart LM, Damiano SR, Li-Wai-Suen CSN, Paxton SJ. Confident body, confident child: Evaluation of a universal parenting resource promoting healthy body image and eating patterns in early childhood-6- and 12-month outcomes from a randomized controlled trial. Int J Eat Disord. 2019;52:121-31. doi:10.1002/eat.22992.

6. Chu JTW, Wadham A, Jiang Y, Whittaker R, Stasiak K, Shepherd M, et al. Effect of MyTeen SMS-based mobile intervention for parents of adolescents: A randomized clinical trial. JAMA Netw Open. 2019;2:e1911120. doi:10.1001/jamanetworkopen.2019.11120.

7. Yap MBH, Mahtani S, Rapee RM, Nicolas C, Lawrence KA, MacKinnon A, et al. A tailored web-based intervention to improve parenting risk and protective factors for adolescent depression and anxiety problems: Postintervention findings from a randomized controlled trial. J Med Internet Res. 2018;20:e17. doi:10.2196/jmir.9139.

8. Corralejo SM, Domenech Rodríguez MM. Technology in parenting programs: A systematic review of existing interventions. J Child Fam Stud. 2018;27:2717-31. doi:10.1007/s10826- 
018-1117-1.

9. Schueller SM, Torous J. Scaling evidence-based treatments through digital mental health. Am Psychol. 2020;75:1093-104. doi:10.1037/amp0000654.

10. Dhaliwal J, Perez AJ, Holt NL, Gokiert R, Chanoine JP, Morrison KM, et al. Why do parents discontinue health services for managing paediatric obesity? A multi-centre, qualitative study. Obes Res Clin Pract. 2017;11:335-43. doi:10.1016/j.orcp.2016.10.285.

11. Linardon J, Cuijpers P, Carlbring P, Messer M, Fuller-Tyszkiewicz M. The efficacy of appsupported smartphone interventions for mental health problems: A meta-analysis of randomized controlled trials. World Psychiatry. 2019;18:325-36. doi:10.1002/wps.20673.

12. Hornby G, Blackwell I. Barriers to parental involvement in education: An update. Educ Rev. 2018;70:109-19. doi:10.1080/00131911.2018.1388612.

13. Hackworth NJ, Matthews J, Westrupp EM, Nguyen C, Phan T, Scicluna A, et al. What influences parental engagement in early intervention? Parent, program and community predictors of enrolment, retention and involvement. Prev Sci. 2018;19:880-93. doi:10.1007/s11121-018-0897-2.

14. O’Toole L, Kiely J, McGillicuddy D, O’Brien EZ, O’Keeffe C. Parental involvement, engagement and partnership in their children's education during the primary school years National Parents Council. 2019.https://researchrepository.ucd.ie/bitstream/10197/9823/2/ Parental\%20Involvement\%20Research\%20Doc.pdf. Accessed March 2021

15. Golan M, Ahmad WA. School-based versus after-school delivery of a universal wellness programme-A randomized controlled multi-arm trial. Eat Behav. 2018;31:41-7. doi:10.1016/j.eatbeh.2018.08.003.

16. Slaten CD, Elison ZM. Interpersonal process group counseling for educationally marginalized youth: The MAGNIFY program. J Sch Couns. 2015;13.

17. Patton MQ. Qualitative research and evaluation methods. Thousand Oaks, CA: Sage Publications; 2002.

18. Rosenberg M. Conceiving the self. Malabar, FL: RE Krieger; 1986. 
19. Gasanov E, Abu Ahmad W, Golan M. Assessment of “young in favor of myself”: A schoolbased wellness program for preadolescents. EC Psychol Psychiatr. 2018;7:13-22.

20. Mendelson BK, Mendelson MJ, White DR. Body-esteem scale for adolescents and adults. J Pers Assess. 2001;76:90-106. doi:10.1207/S15327752JPA7601_6.

21. Kliem S, Schmidt R, Vogel M, Hiemisch A, Kiess W, Hilbert A. An 8-item short form of the Eating Disorder Examination-Questionnaire adapted for children (ChEDE-Q8). Int J Eat Disord. 2017;50:679-86. doi:10.1002/eat.22658.

22. Golan M, Hagay N, Tamir S. The effect of "in favor of myself": Preventive program to enhance positive self and body image among adolescents. PLoS One 2013;8:e78223. doi:10.1371/journal.pone.0078223.

23. Schaefer LM, Burke NL, Thompson JK, Dedrick RF, Heinberg LJ, Calogero RM, et al. Development and validation of the Sociocultural Attitudes Towards Appearance Questionnaire-4 (SATAQ-4). Psychol Assess. 2015;27:54-67. doi:10.1037/a0037917.

24. Rosenberg M. Society and the adolescent self-image. Princeton, NJ: Princeton University Press; 1965.

25. Bearman M, Dawson P. Qualitative synthesis and systematic review in health professions education. Med Educ. 2013;47:252-60. doi:10.1111/medu.12092.

26. Dixon-Woods M, Agarwal S, Jones D, Young B, Sutton A. Synthesising qualitative and quantitative evidence: a review of possible methods. J Health Serv Res Policy. 2005;10:4553. doi:10.1177/135581960501000110.

27. Guagliano JM, Armitage SM, Brown HE, Coombes E, Fusco F, Hughes C, et al. A whole family-based physical activity promotion intervention: Findings from the Families Reporting Every Step to Health (FRESH) pilot randomised controlled trial. Int J Behav Nutr Phys Act. 2020;17:120. doi:10.1186/s12966-020-01025-3.

28. Kilpatrick KD, Kilgus SP, Eklund K, Herman KC. An evaluation of the potential efficacy and feasibility of the resilience education program: A tier 2 internalizing intervention. School Ment Health. 2021. doi:10.1007/s12310-021-09428-8. 
29. Wild CE, Rawiri NT, Willing EJ, Hofman PL, Anderson YC. What affects programme engagement for Māori families? A qualitative study of a family-based, multidisciplinary healthy lifestyle programme for children and adolescents. J Paediatr Child Health. 2021;57:670-6. doi:10.1111/jpc.15309.

30. Bronfenbrenner U. The ecology of human development: Experiments by nature and design. Cambridge, MA: Harvard University Press; 1979.

31. Bronfenbrenner U. Interacting systems in human development. Research paradigms: Present and future. In: Bolger N, Caspi A, Downey G, Moorehouse M, editors. Persons in context: Developmental processes. Cambridge, UK: Cambridge University Press; 1988. p. $25-49$.

32. Kilgus MD, Maxmen JS,Ward NG. Essential psychopathology \& its treatment. 4th ed. New York, NY: WW Norton \& Company; 2015.

33. Zeiler M, Kuso S, Nacke B, Klesges LM, Waldherr K. Evaluating reach, adoption, implementation and maintenance of Internet-based interventions to prevent eating disorders in adolescents: A systematic review. Eur J Public Health. 2020;30:179-88. doi:10.1093/eurpub/ckz130.

34. Amaral ACS, Stice E, Ferreira MEC. A controlled trial of a dissonance-based eating disorders prevention program with Brazilian girls. Psicol Reflex Crit. 2019;32:13. doi:10.1186/s41155-019-0126-3.

35. Morgan J, Fischer JA, Hart LM, Kelly CM, Kitchener BA, Reavley NJ, Yap MBH, and Jorm AF. Long-term effects of Youth Mental Health First Aid training: randomized controlled trial with 3-year follow-up. BMC Psychiatry. 2020;20:487 https://doi.org/10.1186/s12888-020-02860-1.

36. Hayes D, Christie P, Mills M, Lingard, B. Teachers and schooling making a difference: Productive pedagogies, assessment and performance. London, UK: Routledge; 2020. 37. Flannery H, Portnoy S, Daniildi X, Kambakara Gedara C, Korchak G, Lambert D, et al. 
Keeping young people connected during COVID-19: The role of online groups. Arch Dis Child. 2021. doi:10.1136/archdischild-2020-320222.

38. Cohen AO, Breiner K, Steinberg L, Bonnie RJ, Scott ES, Taylor-Thompson K, et al. When is an adolescent an adult? Assessing cognitive control in emotional and nonemotional contexts. Psychol Sci. 2016;27:549-62. doi:10.1177/0956797615627625.

39. Garcia LMT, Hunter RF, de la Haye K, Economos CD, King AC. An action-oriented framework for systems-based solutions aimed at childhood obesity prevention in US Latinx and Latin American populations. Obes Rev. 2021:e13241. doi:10.1111/obr.13241.

40. Waterloo SF, Baumgartner SE, Peter J, Valkenburg PM. Norms of online expressions of emotion: Comparing Facebook, Twitter, Instagram, and WhatsApp. New Media Soc. 2018;20:1813-31. doi:10.1177/1461444817707349.

\section{Table Titles and Figure Legends}

Table 1 Content and description of the program sessions

Table 2 Overview of measures used to evaluate program efficacy in students and parents

Table 3 From allocation to analysis - number and percentages of participants in both digital modes along research stages

Figure 1 Screenshots (translated to English) from the "In Favor of Myself" smartphone application. Figure 2 Number of Dyad's shared assignments' submission (parental component arm) delivered through WhatsApp vs. the special application

Figure 3 WhatsApp mode: Youths' self-esteem in the three groups over time

Figure 4 WhatsApp mode: Number of advertising strategies identified in each study arm over time 
Figures
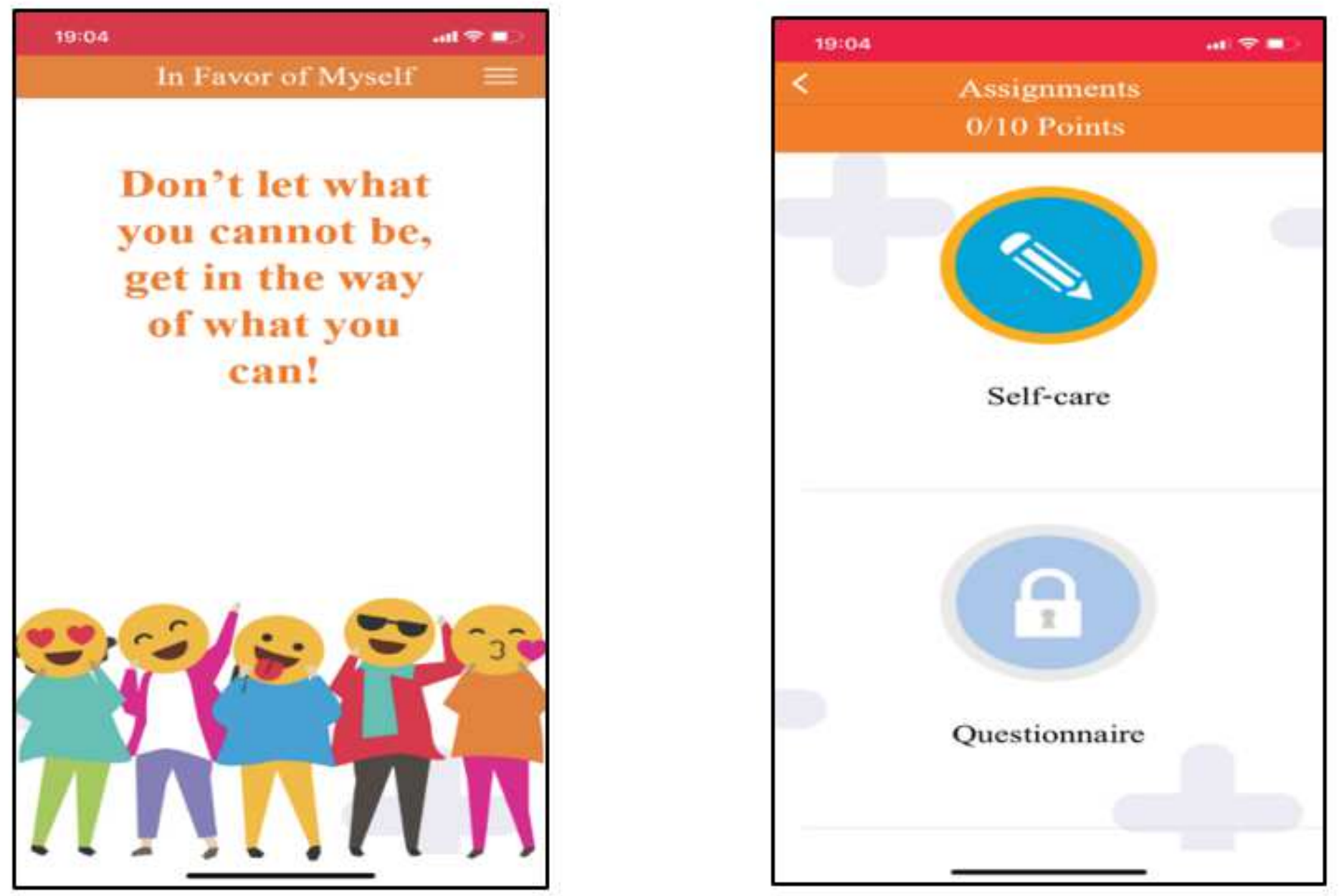

Figure 1

Screenshots (translated to English) from the "In Favor of Myself." Smartphone application. 


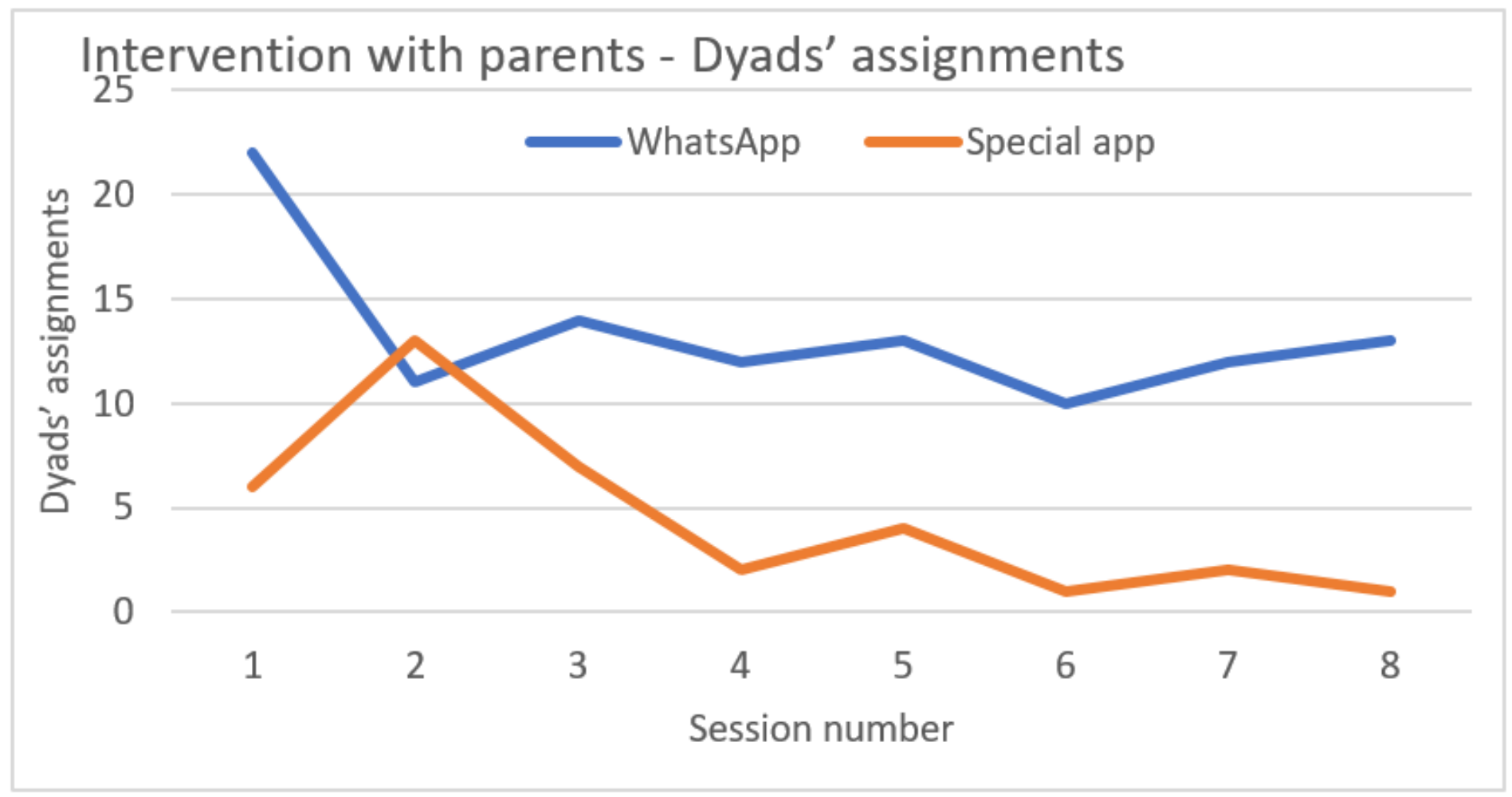

Figure 2

Number of Dyad's shared assignments' submission (parental component arm) delivered through WhatsApp vs. the special application

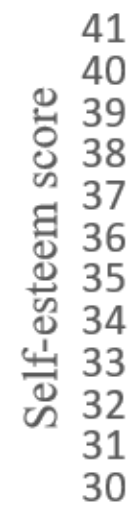

41

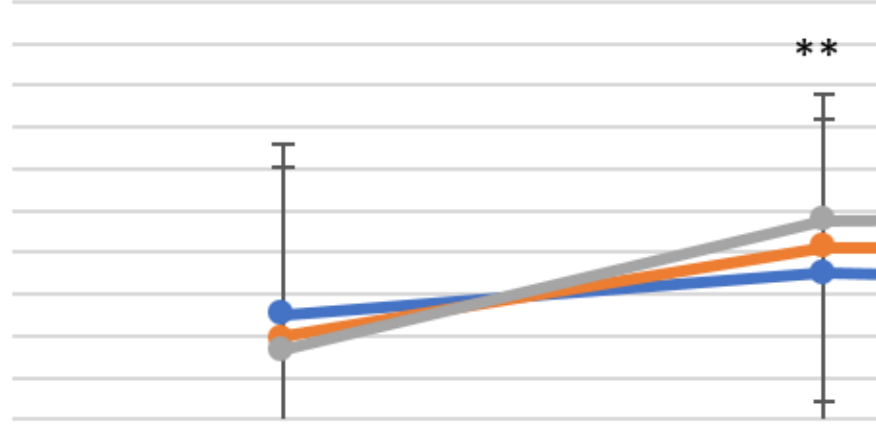

$\mathrm{T} 1$

$\mathrm{T} 2$

T3

Control group

- Preadolescents-only intervention group

Parental-component intervention group

\section{Figure 3}

WhatsApp Mode: Youth's Self-esteem in the three groups over time ${ }^{\star \star} p=0.02$ between group-differences 


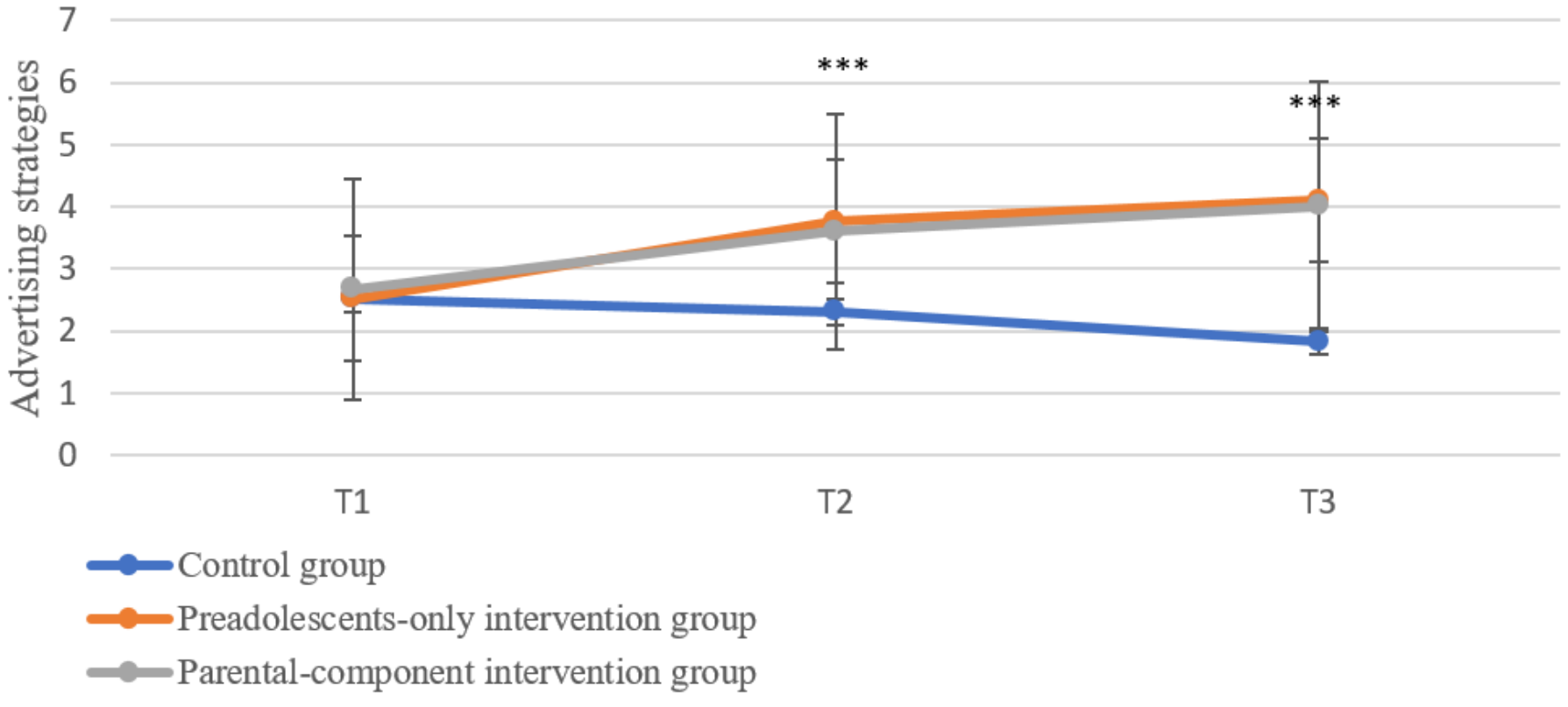

Figure 4

WhatsApp mode: Number of advertising strategies identified in each study arm over time ${ }^{\star *} p<0.001$ between group-differences 